\title{
Diversity and Biological Activities of Endophytic Fungi at Al-Qassim Region
}

\author{
Nahla Tharwat Elazab ${ }^{1,2}$ \\ ${ }^{1}$ Department of Botany, Faculty of Science, Mansoura University, Egypt \\ ${ }^{2}$ Department of Biology, Faculty of Science and Art, Al-Qassim University, Saudi Arabia \\ Correspondence: Nahla Tharwat Elazab, Department of Botany, Faculty of Science, Mansoura University, Egypt. \\ E-mail: n_tharwat@yahoo.com / nahlatharwat83@gmail.com
}

Received: October 26, 2019

Accepted: November 10, 2019

Online Published: November 16, 2019

doi:10.5539/jmbr.v9n1p160

URL: https://doi.org/10.5539/jmbr.v9n1p160

\begin{abstract}
In recent year's endophytic fungi has become a major concern on their host plants by enhancing their growth, increasing their fitness, strengthening their tolerances to abiotic and biotic stresses, and promoting their accumulation of secondary metabolites. Kingdom of Saudi Arabia has a wide range of flora which may be a rich source of endophytic fungi so that, the present study involves diversity and bioactivity of the endophytic fungal community in Al-Qassim region from 15 wild plants 162 isolates were obtained and identified. Among them, the most common isolates were Aspergillus niger, Aspergillus terreus, Aspergillus ochraceous and Trichoderma viride, these four endophytic isolates were examined for its antagonistic effect against six phytopathogenic fungi using two different assays, Dual-culture and Culture filtrate. Trichoderma viride recorded the most significant growth inhibition of almost pathogenic fungi followed by the three endophytic Aspergillus spp. In addition, these four endophytic fungi were screened for the production of some extracellular enzymes such as protease, cellulose, amylase, pectinase and xylanase. Our results show the ability of these isolates to produce these extracellular enzymes so this indicated the possible role of endophytic fungi as a biocontrol agent of plant disease.
\end{abstract}

Keywords: Biocontrol, Endophytic fungi, Extracellular enzymes, Phytopathogenic fungi, Wild plants

\section{Introduction}

Endophytes are microorganisms including fungi and bacteria that spend the whole of their Lifecycle colonizing in living tissue of different plants typically without causing any conspicuous symptoms of disease (Sandhu et al., 2014). Endophytic fungi are part of the plant microbiome and are ubiquitously found across plant species and ecosystems (Arnold, 2007). It is obvious that the endophytic diversity is differed according to the host identity and its community relies upon geographic status and seasonal changes (Johnston et al., 2012). During the long period of co-existence and evolutionary processes, different relationships have been established between endophytic fungi and their plant host recognized as: (a) a continuum of mutualism, (b) antagonism, and (c) neutralism (Sun et al., 2012). Genetically, nutrient level, and ecological habitats of the host plants are considered as the pressure-choice factors on the population structure of the endophytic fungi that, in turn, confer some kinds of benefits as growth induced, increased resistance to disease, and/or herbivore (Atugala \& Deshappriya, 2015).

Endophytic fungi have functional roles in agriculture and food safety, plant growth, crop protection, phytoremediation and ecological balance (Sudha et al., 2016). They act as bio-control agents due to its ability to produce antifungal substances that are capable of inhibiting the growth and spore germination of microbial pathogens so they consider a promising natural resource of future bio-control agents for forestry management (Rodriguez et al., 2009).

Recently, endophytes are seen as a wellspring of novel bioactive metabolites such as alkaloids, terpenoids, steroids, quinones, isocoumarins, lignans, phenylpropanoids, phenols, and lactones offering the potential for medicinal, agrarian and industrial imposition (Gouda et al., 2016). endophytic fungi have gained impetus due to their enormous potential to produce a myriad of medicinally important metabolites. Therefore, exploring endophytic fungi that inhabit plant species with medicinal properties would provide ample opportunities to discover new metabolites with potential bioactivity (Wiyakrutta et al., 2004). The bioactivity of endophytes derivatives involves anti- inflammatory, antimicrobial, antitumor and antiviral (Selim et al., 2012). Moreover, 
some endophytic fungal strains has the ability to produce bioactive metabolites as taxol, pestaloside, torreyanic acid and enzymes like Xylanase, Isoflavonoids, Asparaginase (Theantana et al., 2007; Radji et al., 2011).

Kingdom of Saudi Arabia is a large country, talented with a wide range of flora, including trees, shrubs and herbs of hydrocarbon, palatable and has medical effects (Al-Rahmah et al., 2013). The country possesses a unique genetic diversity in the form of ecotypes of tree species and more than 280 other grasses species in various ecological/geographical regions. Only relatively few plants have been examined for the presence of endophytic fungi in Saudi Arabia (Gherbawy \& Gashgari, 2014; Gashgari et al., 2016) and no studies carried out in Al-Qassim region in this context, this study aim to isolation of endophytic fungi associated with different plants collected from Al-Qassim region and to test its antagonistic activities against some phytopathogenic fungi and the ability of production of some extracellular enzymes.

\section{Material and Methods}

\subsection{Plant Materials Collection:}

A total of fifteen healthy and mature wild plants were collected from Al-Qassim region (lies between longitudes $41^{\circ} 30^{\prime}$ and $44^{\circ} 45^{\prime} \mathrm{E}$, and latitudes $24^{\circ} 25^{\prime}$ and $27^{\circ} 15^{\prime} \mathrm{N}$ ), Kingdom of Saudi Arabia during the period from January to March 2019. After plant selection, disease-free parts of the plant, that is, stem, root, and leaves, were excised with a sterile scalpel and placed in sterilized poly ethylene bags, stored at $4^{\circ} \mathrm{C}$ directly after collection and transported to the laboratory. The plant samples were classified to different families and listed in the Table 1.

Table 1. List of wild plant collected from Al-Qassim region, Kingdom of Saudi Arabia

\begin{tabular}{ll}
\hline Scientific name & Family \\
\hline Sisymbrium irio & Brassicaceae \\
Rumex vesicarius & Polygonaceae \\
Brassica rapa & Brassicaceae \\
Imperata cylindrica & Poaceae \\
Launaea mucronata & Asteraceae \\
Malva parviflora & Malvaceae \\
Ocimum basilicum & Lamiaceae \\
Anthemis cotula & Asteraceae \\
Cleome africana & Cleomaceae \\
Eremobium aegyptiacum & Brassicaceae \\
Moltkiopsis ciliata & Boraginaceae \\
Paronychia desertorum & Caryophyllaceae \\
Erodium laciniatum & Geraniaceae \\
Zygophyllum simplex & Zygophyllaceae \\
Zilla spinosa & Brassicaceae \\
\hline
\end{tabular}

\subsection{Endophytic Fungi Isolation}

The endophytes were isolated using a modified method described by Dobranic et al. (1995). The plant samples were carefully washed under running tap water to get rid of dust and soil debris. Then, each sample was cut into small fragments under aseptic condition measuring from 0.5 to $1 \mathrm{~cm}$ using sterile surgical scalpel. The fragments were surface sterilized by sequentially dipping into $70 \%$ ethanol for five seconds, $4 \%$ sodium hypochlorite solution for 90 seconds, sterile distilled water for 10 seconds. About 5-6 segments after dried under control condition were placed mycological medium, that is, Potato Dextrose Agar (PDA: $300 \mathrm{~g} / \mathrm{L}$ diced potatoes, $20 \mathrm{~g} / \mathrm{L}$ dextrose and $20 \mathrm{~g} / \mathrm{L}$ agar) with tetracycline $(10 \mathrm{mg} / \mathrm{L})$ to inhibit the bacterial contaminant then incubated $25 \pm$ $2^{\circ} \mathrm{C}$ for 21 days. After incubation period the purity of each fungal culture were transferred to PDA slant tubes at (4-5) ${ }^{\circ} \mathrm{C}$ and used as stock culture for further experimental studies. The fungi were identified based on morphological and reproductive characteristics according to the methods described by Domsch et al. (1980).

The colonization frequency (CF \%) and the percentage of the dominant endophytic fungi percentage were calculated (Petrini \& Fisher 1988; Kumar \& Hyde, 2004).

$$
C F \%=\frac{\text { number of segments colonized by endophyte }}{\text { Total number of segments analysis }} \times 100
$$

\subsection{Antagonistic Activity of Endophytic Fungi in vitro}

\subsubsection{Dual-culture Method}

The antagonistic effect of the most dominant four endophytic fungi isolated from the selected wild plants against 6 selected phytopathogenic fungi (Fusarium solani, Stemphylium sp., Cladosporium sp., Aspergillus fumigatus, 
Rhizoctonia solani and Macrophomina phaseolina) obtained from The Promising Research Center in Biological Control and Agricultural Information, Qassim University, has been carried out by dual culture technique (Katoch \& Pull, 2017).

The Petri plates containing 15-20ml PDA were prepared. Discs of 5 days old pure cultures of isolated endophytes and pathogens (5mm in diameter) were co-cultured at the two opposite ends of the plates and incubated at $25 \pm 2^{\circ} \mathrm{C}$ after sealing them with parafilm. For control, a disc from each pathogenic fungus was placed at one end of the PDA petri dish alone without endophyte. These treatments were carried out in triplicates. After 7 days of incubation, the diameter of radial growth of the endophytes and the pathogen were measured and recorded in each treatment and the percentage of growth inhibition (GI\%) of the phytopathogenic fungi was calculated using this formula (Ghildial \& Pandey, 2008).

\subsubsection{Culture filtrate assay}

$$
\text { GI } \%=1-\left(\frac{\text { Diameter of pathogen colony in treatment }}{\text { Diameter of pathogen colony in control }}\right) \times 100
$$

Each endophyte was cultured in $50 \mathrm{~mL}$ of potato dextrose broth (PDB) in $250 \mathrm{~mL}$ Erlenmeyer flasks by inoculating two plugs $(0.5 \mathrm{~cm})$ of actively growing endophytic fungus and incubated for 10days in rotatory shaker $(150 \mathrm{rpm})$ at $25 \pm 2^{\circ} \mathrm{C}$. The cultures were centrifuged to remove biomass so as to collect the broth containing antagonist metabolites (Dennis \& Webster, 1971). Endophytic culture filtrate $(200 \mu \mathrm{L})$ was spread on PDA plates to test their antagonistic activity. On drying of filtrate, respective pathogenic fungus $(0.5 \mathrm{~cm}$ plug $)$ was inoculated at the center of PDA plate. Simultaneously, PDA plates containing pathogenic fungi without endophytic culture filtrate served as control, and then incubated at $25 \pm 2^{\circ} \mathrm{C}$. After 7 days, the radial growth of pathogen in the presence/absence of endophytic culture filtrate was monitored and the percentage growth inhibition (GI \%) was calculated for respective culture filtrate using the above formula (2).

\subsection{Assay of some extracellular enzymes}

The production and activity of extracellular enzymes by fungal endophytes were assessed by growing them on Yeast-Malt (YM) agar media (YM: $10 \mathrm{~g} / \mathrm{L}$ glucose, $5 \mathrm{~g} / \mathrm{L}$ peptone, $3 \mathrm{~g} / \mathrm{L}$ yeast extract, $3 \mathrm{~g} / \mathrm{L}$ malt extract, $1.5 \%$ agar, pH 6.7) (Molina et al., 2012) and placing $5 \mathrm{~mm}$ fungal plugs on the YM agar media supplemented with dissolved and specific indicative substrates. After incubation for 3-5 days depending on the growth rates of fungal endophytes at $28^{\circ} \mathrm{C}$, the appearance of clear zone surrounding the fungal colony was measured after adding specific reagent and used as indicator for extracellular enzymatic activities. All assays were performed in triplicate.

\subsubsection{Proteolytic Activity}

The YM agar medium containing $1 \%$ gelatine was used to determine the fungal protease enzyme activity. After incubation, the degradation of gelatine was seen as clear zoon around the colonies by using acidic mercuric chloride as an indicator.

\subsubsection{Cellulase Activity}

The appearance of clear zone around the fungal colony grown on YM medium supplemented with $1 \%$ cellulose or carboxymethylcellulose (CMC) was measured, in order to assess the fungal cellulolytic activity after adding iodine solution as indicator.

\subsubsection{Amylolytic Activity}

Amylase activity was assessed by growing the fungal isolates on YM agar medium supplemented with $1 \%$ soluble starch. After incubation, the plates were flooded with $1 \%$ iodine. The appearance of clear zones around fungal growth was measured to determine the amylolytic activity.

\subsubsection{Pectinolytic Activity}

Pectinolytic activity was determined by growing the fungi in $1 \%$ Pectin YM containing medium. After the incubation period, the plates were flooded with $1 \%$ aqueous solution of hexadecyl trimethyl ammonium bromide. A clear zone formed around the fungal colony indicated the activity of pectinase enzyme.

\subsubsection{Xylanolytic Activity}

Yeast-Malt agar medium supplemented with $1 \%$ xylan of corncobs was used in order to measure the fungal xylanolytic activity. After incubation period, screening the xylanase activity was appeared as a clear zone around the fungal colony as a result of using absolute ethyl alcohol to indicate the xylan bio degradation.

\subsection{Statistical Methods}

Data obtained were statistically analyzed using Analysis of Variance (ANOVA) Microsoft EXCEL 2010. 


\section{Results}

3.1. Isolated Endophytic Fungi

Fortunately, according to our scientific, this is considering the first report describing the isolation of endophytic fungi residing in wild plants in Al-Qassim region, Kingdom of Saudi Arabia. A total of 162 isolates belonging to 15 species and 10 genera were isolated from 15 wild plants (Table 2). These isolates were identified as follow: Alternaria (12 isolates), Aspergillus (77 isolates), Colletotrichum (2 isolates), Fusarium (13 isolates), Nigrospora (2 isolates), Penicillium (12 isolates), Rhizopus (6 isolates), Curvularia (6 isolates), Trichoderma (20 isolates) and Trichocladium (12 isolates).

The most dominant isolates can be arranged as follows: Aspergillus spp. represent the highest frequency (47.6\%) followed by Trichoderma sp.12.3\%, Fusarium sp. 8.1\%; while each of Alternaria sp. Penicillium sp. and Trichocladium sp. is represent by $7.4 \%$ however Rhizopus sp. and Curvularia sp. is 3.7\% whereas the lowest frequency (1.2\%) in Colletotrichum sp. and Nigrospora sp. The most dominant fungal species were recovered by Aspergillus niger and Trichoderma viride recording $13 \%$ and $12.3 \%$, respectively. On the other hand, Colletotrichum sp. and Nigrospora sp. had the least dominance percentage (1.2\%), (Figure.1).

Among the tested organisms, the most prevalent fungi were Aspergillus niger and Trichoderma viride with colonization frequency $87.5 \%$ followed by Aspergillus terreus $75 \%$, then Aspergillus flavus and Aspergillus ochraceous $62.5 \%$, whereas Colletotrichum sp. and Nigrospora sp. exhibited the lowest colonization frequency percentage $12.5 \%$.

Table 2. Colonization frequency percentage and dominant fungi percentage of endophytic fungi isolated from wild plant

\begin{tabular}{cccc}
\hline Endophytic fungi & Number of isolates & CF \% & Dominant fungi\% \\
\hline 1. Alternaria alternata & 12 & 50.0 & 7.41 \\
2. Aspergillus niger & 21 & 87.5 & 12.96 \\
3. Aspergillus flavus & 15 & 62.5 & 9.25 \\
4. Aspergillus terreus & 15 & 75.0 & 9.25 \\
5. Aspergillus oryzae & 3 & 25.0 & 1.85 \\
6. Aspergillus ochraceous & 18 & 62.5 & 11.11 \\
7. Aspergillus fumigates & 5 & 25.0 & 3.10 \\
8. Colletotrichum sp. & 2 & 12.5 & 1.23 \\
9. Curvularia sp. & 6 & 25.0 & 3.70 \\
10. Fusarium solani & 13 & 37.5 & 8.02 \\
11. Nigrospora sp. & 2 & 12.5 & 1.23 \\
12. Penicillium chrysogenum & 12 & 50.0 & 7.40 \\
13. Rhizopus sp. & 6 & 37.5 & 3.70 \\
14. $\quad$ Trichoderma viride & 20 & 87.5 & 12.34 \\
15. Trichocladium sp. & 12 & 25.0 & 7.41 \\
\hline Total number of isolates & 162 & & \\
\hline
\end{tabular}

$\mathrm{CF}=$ Colonization Frequency 


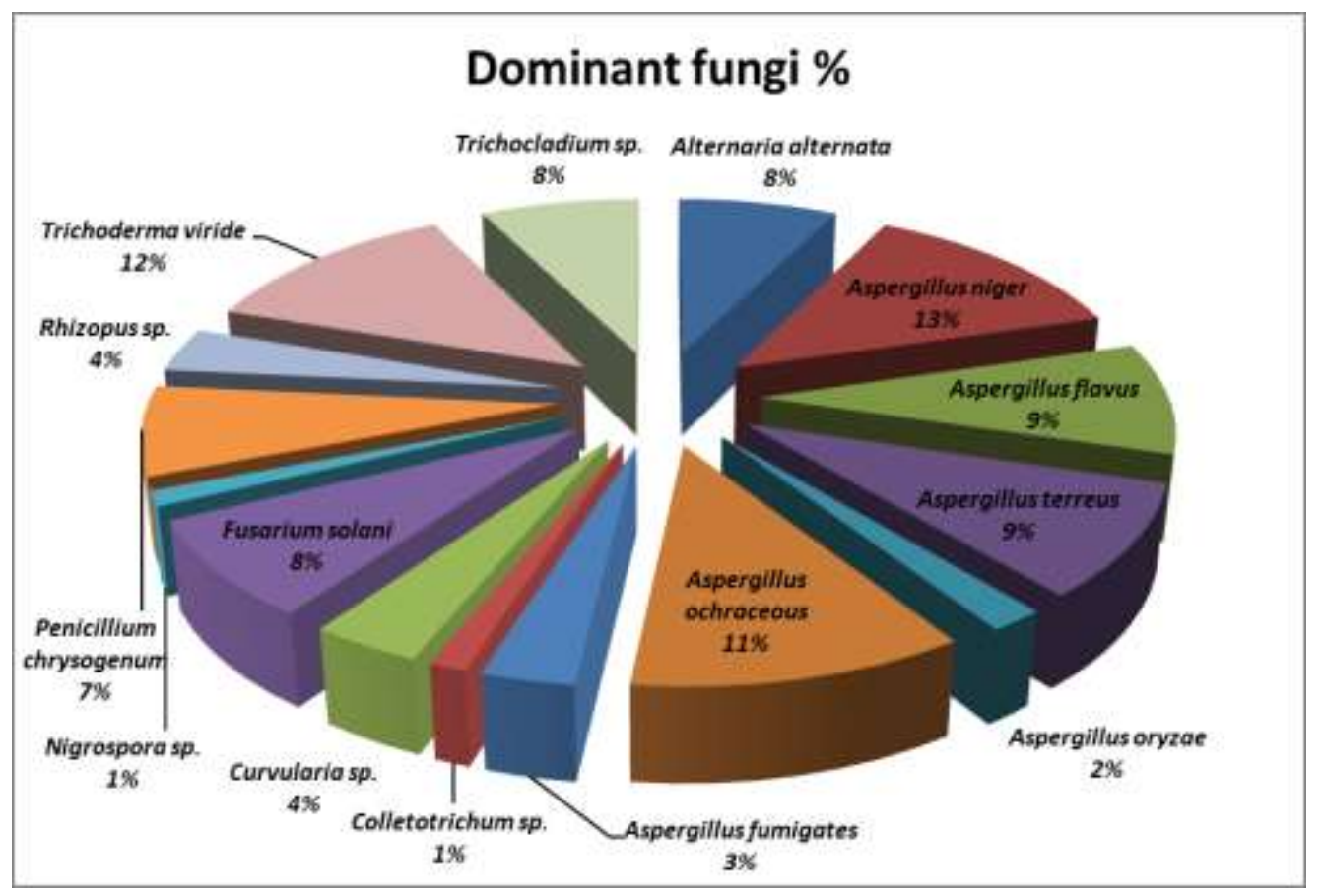

Figure 1. The dominant fungi percentage of the endophytes isolated from wild plants

\subsection{Antagonistic activity of endophytic fungi in vitro}

\subsubsection{Dual culture technique}

By dual culture assay, the antagonistic action of the four selected endophytic fungal strains (according to their high CF \%) Aspergillus niger, Aspergillus terreus and Aspergillus ochraceous, Trichoderma viride against six plant pathogenic fungi, namely, Fusarium solani, Stemphylium sp., macrophomina phaseolina, Cladosporium sp., Rhizoctonia solani and Aspergillus fumigatus was evaluated. The endophyte Trichoderma viride showed significant antifungal activity with growth inhibition of more than $70 \%$ against Fusariumsolani, Cladosporium sp. and Aspergillus fumigatus. Whereas growth inhibition of Stemphylium sp, Fusarium solani and Cladosporium sp.is higher than $60 \%$ in the presence of Aspergillus ochraceous however in case of endophyte Aspergillus niger, the percentage of growth inhibition reached to $60 \%$ against Cladosporium sp and Macrophomina phaseolina. Also Aspergillus terreus has affect above 60\% against Fusarium solani and Cladosporium sp.

On the other hand, Aspergillus ochraceous has low antagonistic effect on macrophomina phaseolina and Aspergillus fumigates (33.3 and $31.7 \%$, respectively) as the same effect of Aspergillus terreus against Rhizoctonia solani as presented in Table (3) and Figure (2).

Table 3. Antagonistic activity of endophytic fungi against some phytopathogenic fungi in vitro by dual Culture assay

\begin{tabular}{|c|c|c|c|c|}
\hline & \multicolumn{4}{|c|}{ Endophytes } \\
\hline & Aspergillus niger & $\begin{array}{l}\text { Aspergillus } \\
\text { ochraceous }\end{array}$ & $\begin{array}{c}\text { Aspergillus } \\
\text { terreus }\end{array}$ & $\begin{array}{c}\text { Trichoderma } \\
\text { viride }\end{array}$ \\
\hline Pathogenic fungi & \multicolumn{4}{|c|}{ Percentage of growth inhibition (GI \%) } \\
\hline Fusarium solani & 53.8 & 68.0 & 64.1 & 74.3 \\
\hline Stemphylium sp. & 49.3 & 63.7 & 50.7 & 62.3 \\
\hline Macrophomina phaseolina & 60.0 & 33.3 & 44.0 & 52.0 \\
\hline Cladosporium sp. & 62.5 & 62.5 & 65.0 & 77.5 \\
\hline Rhizoctonia solani & 42.8 & 50.0 & 35.7 & 57.1 \\
\hline Aspergillus fumigatus & 58.8 & 31.7 & 48.2 & 76.5 \\
\hline
\end{tabular}




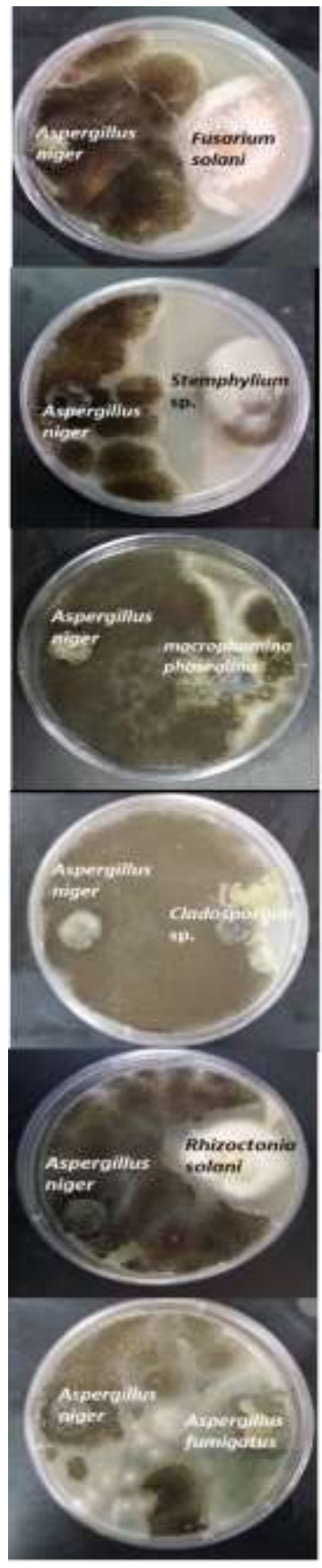

A

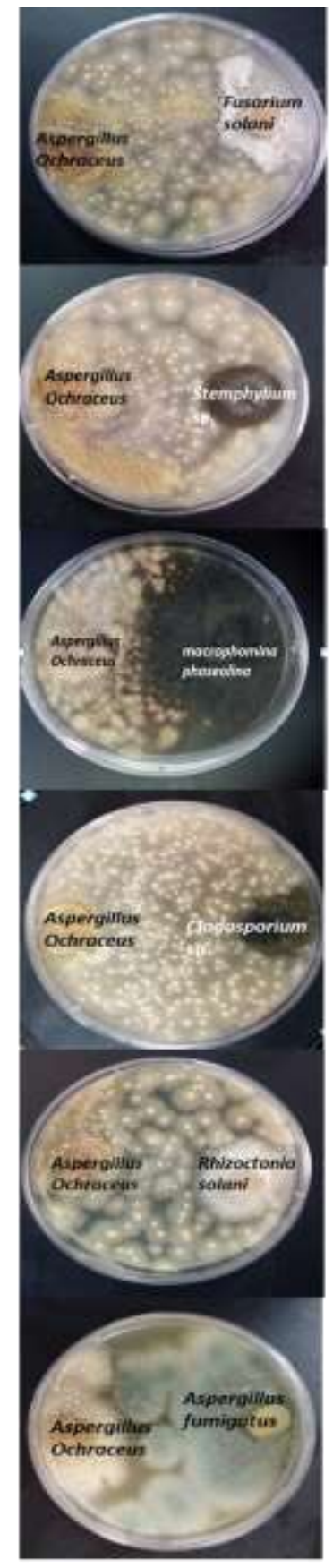

B

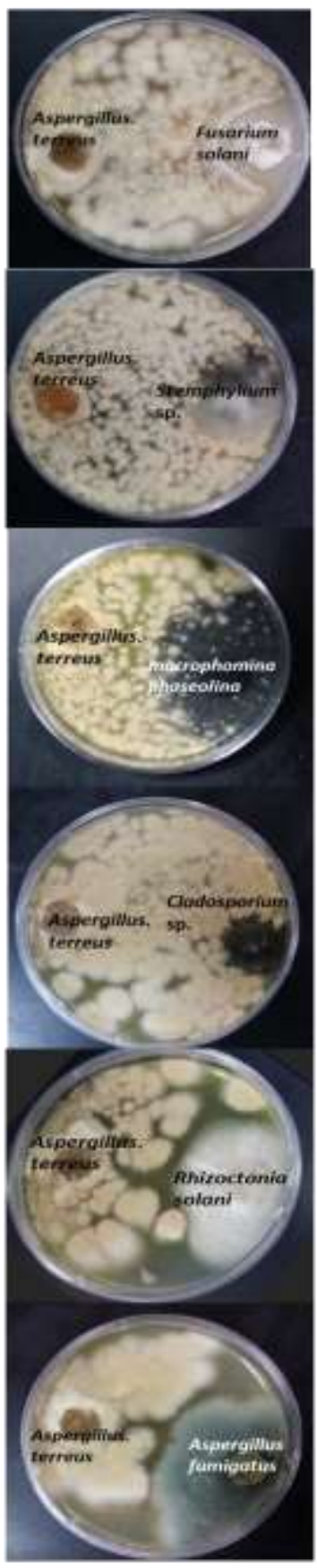

C

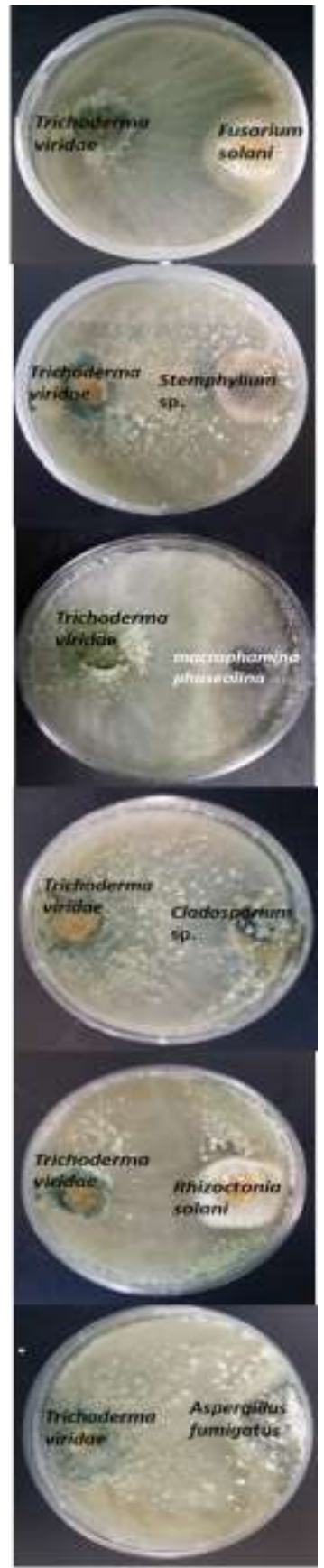

$\mathbf{D}$

Figure 2. Antagonistic activity of endophytes Aspergillus niger (A), Aspergillus ochraceous (B), Aspergillus terreus (C) and Trichoderma viride (D) against some phytopathogenic fungi in vitro by dual culture assay

\subsubsection{Culture filterate assay}

In culture filtrate assay of the four endophytic fungal isolates collected after five days of incubation against the test fungal phytopathogens was evaluated and showed variable growth inhibition according to the used antagonists where, Trichoderma viride displayed broad range of antagonistic activity i.e., active against almost all the plant pathogens tested but Aspergillus niger recorded the least antagonistic efficiency in some cases as shown in Table (4). 
Table 4. Antagonistic activity of endophytic fungi against some phytopathogenic fungi in vitro by Culture filtrate assay

\begin{tabular}{lcccc}
\hline & \multicolumn{3}{c}{ Endophytes } \\
\cline { 2 - 5 } & $\begin{array}{c}\text { Aspergillus } \\
\text { niger }\end{array}$ & $\begin{array}{c}\text { Aspergillus } \\
\text { ochraceous }\end{array}$ & Aspergillus terreus & $\begin{array}{c}\text { Trichoderma } \\
\text { viride }\end{array}$ \\
\hline Pathogenic fungi & \multicolumn{4}{c}{ Percentage of growth inhibition (GI \%) } \\
\hline Fusarium solani & 52.9 & 70.5 & 64.7 & 74.1 \\
Stemphylium sp. & 46.6 & 68.0 & 49.3 & 65.3 \\
Macrophomina phaseolina & 59.5 & 41.7 & 43.0 & 62.0 \\
Cladosporium sp. & 56.2 & 70.0 & 61.2 & 75.0 \\
Rhizoctonia solani & 42.6 & 52.0 & 33.3 & 54.6 \\
Aspergillus fumigatus & 55.3 & 29.4 & 47.1 & 70.6 \\
\hline
\end{tabular}

\subsection{Extracellular enzyme activity of endophytes}

The date in Figure (3) shows variations in the production of extracellular enzymes by the endophytic fungal isolates. Aspergillus niger showed high performance in enzymes production where, it achieved the maximum protease, amylase and xylanse production. While Trichoderma viride and Aspergillus ochraceous exhibited the maximum production of cellulases and pectinases production, respectively. All isolates achieved high cellulase activity except in case of Aspergillus ochraceous but this isolate recorded the maximum production of pectinases. Amylase and pectinase were produced moderately by Aspergillus terreus which displayed the minimum Pectinolytic activity. Endophytic Trichoderma viride shows intermediate enzymes production in all cases but its cellulolytic activity is distinguished in comparison to the other isolates.

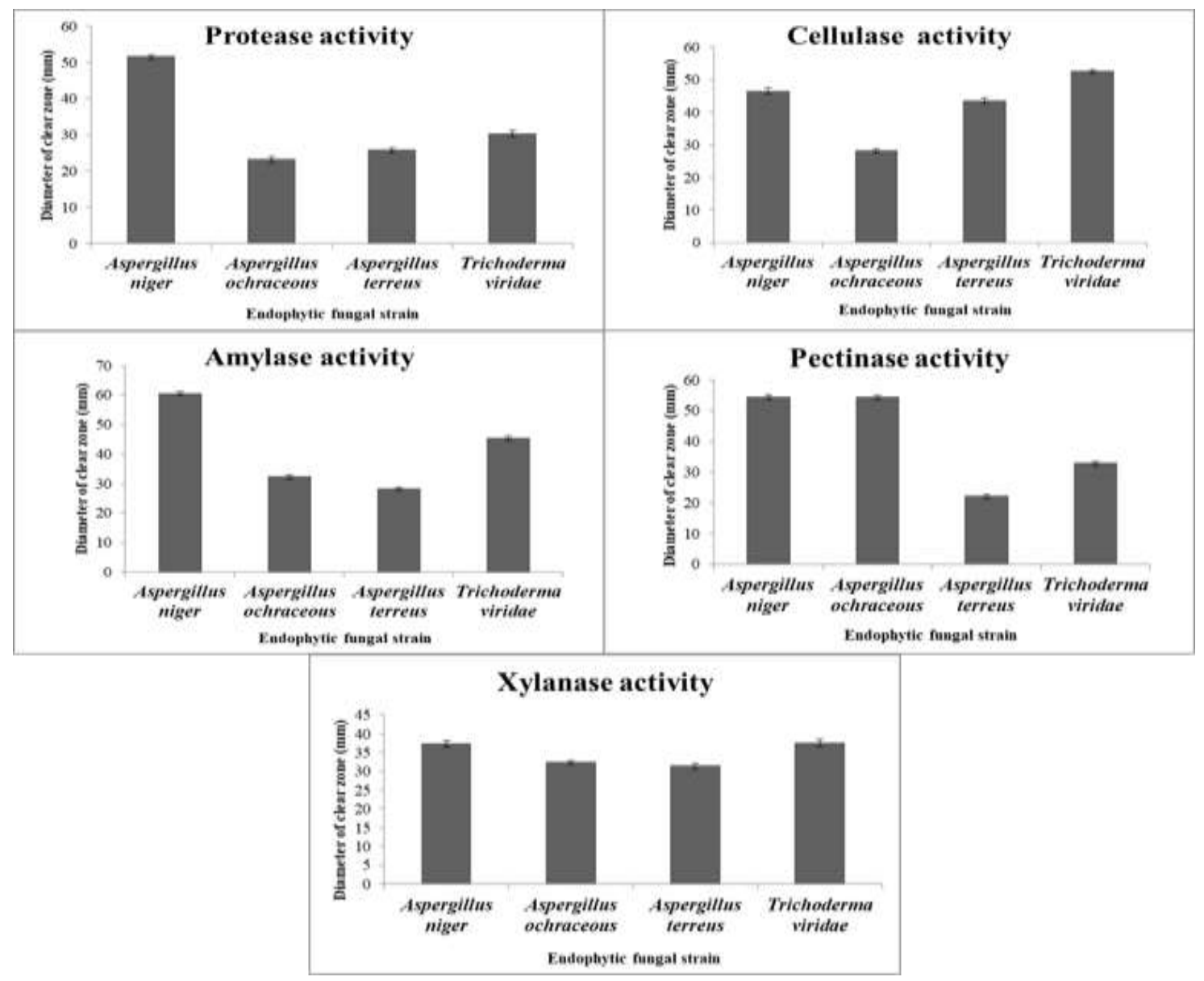

Figure 3. The extracellular enzymes activities of isolated endophytic fungi. 


\section{Discussion}

Today, more and more studies have focused on the endophytic fungi extracted from various plants nevertheless a large part of this natural wealth remains unexplored (Porras \& Bayman, 2011). Ecosystem plays an important role in the process of endophytism or vice versa through host disease resistance (Fouda et al., 2015), adaptation to unique niches, plant secondary metabolism (Singh et al., 2011). In this study, 162 endophytic fungal strains belonging to 15 species and 10 genera were isolated from different parts of 15 wild plants collected from Al-Qassim region, Kingdom of Saudi Arabia and identified using their morphological and reproductive characteristics.

Endophytes can play a major role in plants response to abiotic stresses (salinity); however, unfavorable environmental factors can affect their diversity and colonization density (Lata et al., 2018). Colonization frequency data shows that different endophytic fungi inhabited different plant tissues to different extent. This difference in inhabiting potential of the endophytic fungi shows that, each endophyte exhibited different degrees of affinity towards different tissues of the plant (Katoch et al., 2017). A possible explanation for the relatively low overall fungal diversity noted in the present study could be due to the high drought and the desert nature of Saudi Arabia.

According to classical mycology, most species of endophytic fungi have been described based on their morphological features (Domsch et al., 1980). However, the use of morphological features was problematic for phylogenetic systematics of hypogeous ascomycetes due to a small set of morphological characteristics and homoplasy (Phongpaichit et al., 2007). In this study, most of fungal isolates belong to Ascomycota, however, zygomycota represented only by one genus (Rhizopus) confirming the previous reports of Kembel \& Mueller (2014) that endophytic fungi are mainly ascomycetes.

Our results were similar to EL-Nagerabi et al. (2013) who found that the great biodiversity in Aspergillus species isolated as endophytes from Ziziphus plant grown in arid region. Also, Aspergillus niger was the dominant endophytic fungus in Canavalia cathartica (Dorothy \& Kandikere, 2009). Several endophytic Trichoderma fungal strains were isolated from various plants belong to family Cuppressaceae (Hosseyni-Moghaddam \& Soltani, 2013) and Some species of Alternaria, Colletotrichum, Fusarium, Nigrospora,Penicillium, Rhizopus, Curvularia and Trichocladium have been reported as endophytes for many plants (El-Morsy, 2000; Fouda et al., 2015; Prathyusha et al., 2015; Gashgari et al., 2016). Some of the isolated fungal strains in the current study for example, Alternaria. alternata, different Aspergillus species and Fusarium solani are well-known plant pathogens. The fungal activity as an endophyte in one plant or as a pathogen in another one relied on the balance between the pathogenicity and endophytism of the microorganism in different hosts (Gashgari et al., 2016).

The biological control which depends on the use of antagonistic organisms that broadly/specifically target the pathogen has become highly pivotal field, and in many cases, complementing or even replacing the chemical control which has several negative effects. Antagonistic fungi play an important role in biological control (Pandya \& Saraf, 2010). Endophytes can act as potential biological control agents through their ability to reduce disease by various mechanisms as production of volatiles and nonvolatile metabolites (Ting et al., 2010) or stimulation of host defense (Benhamou et al., 2000; Walters et al., 2005 and El-Hasan et al., 2009).

Endophytic fungal spp. produces different types of proteins some of them act on the extraction of nutrients which important for the fungal growth and other type of proteins have an inhibitory effect on plant pathogens activities acting as pathogenicity related proteins(PR) which causes distortion of cell walls of the pathogenic fungi (Li et al., 2004).

In this study we recognize the role of endophytes in biocontrol, their antagonistic behavior against major phytopathogens, the most dominant four fungal endophytes isolated from wild plants were tested in vitro for their ability to control the growth of the most common and economically important fungal pathogens in Al-Qassim region by dual-culture assay and culture filtrate assay. The results demonstrated that an endophytic fungal strain, Trichoderma viride had a great negatively impact on the growth of the phytopathogenic fungi to the extent that the growth of some pathogen was restricted to its inoculation site and this may be attributed to competition process and production of diffusible antibiotics, these data is the same indicated by Whipps (2001) and Talapatra et al. (2017). Also confirmed our data by Benitez et al. (2004) who reported that the genus Trichoderma spp. have been investigated as the most studied and broadly used economically efficient biological control agent against different phytopathogens to reduce the disease incidence. Aspergillus spp. isolates were very effective against the tested phytopathogens but not recommended as a biological control agents because of their carcinogenic properties. 
Recently through many researches, it is proved that Endophytes have the ability to produce numerous extracellular enzymes. The ability of endophytes to produce extracellular enzymes may help them to degrade polysaccharides and proteins in order to become available during the plant senesce as suggested by Toghueo et al. (2017). Hydrolytic extracellular enzymes as cellulase and pectinase are play the key role in the extraction of its nutritional requirements from hosts and bio-resistance action against microbial pathogenic infection through its destructive action on fungal cell wall (Fouda et al., 2015). Moreover, Mandyam and Jumpponen (2005) suggested the important role of endophytic fungi in improvement of host plant growth through its production of various extracellular enzymes that can access and utilize sources of $\mathrm{C}, \mathrm{N}$ and $\mathrm{P}$ in soil.

Our current results indicated that the four selected endophytic fungi have the ability to produce some extracellular enzymes that concerning with gelatine, cellulose, starch, pectin and xylan degradation. Among the isolates, Aspergillus niger and Trichoderma viride were superior in protease, cellulase, amylase and xylanase production while, regarding to pectinase production Aspergillus ochraceous was eminent. It has been proved that $72 \%$ of isolated endophytes were an efficient amylase and protease producers (Amirita et al., 2012). Trichoderma species are well known producers of degradative enzymes like chitinases (Di Pietro et al., 1993) and cellulases (Sternberg \& Doval, 1980) and are currently exploited industrially for enzyme production, bio-control of plant diseases (Harman et al., 2004) and plant growth promotion (Samuels, 1996).

Finally, we can say, Al-Qassim region, Kingdom of Saudi Arabia has various wild plants which harbored numerous endophytic fungal spp. that may play different roles in biological control of plant pathogens and production of some important industrial enzymes and further studies are required to include a great number of plants in this region.

\section{References}

Al-Rahmah, A.N., Mostafa, A.A., Abdel-Megeed, A., Yakout, S.M. \& Hussein, S.A. (2013). Fungicidal activities of certain methanolic plant extracts against tomato phytopathogenic fungi. African Journal of Microbiology Research, 7(6), 517-524. http://doi.org/10.5897/AJMR12.1902

Amirita, A., Sindhu, P., Swetha, J., Vasanthi, N.S. \& Kannan, K.P., (2012). Enumeration of endophytic fungi from medicinal plants and screening of extracellular enzymes. World Journal of Science and Technology, 2(2), 13- 19.

Arnold, A.E. (2007). Understanding the diversity of foliar endophytic fungi: progress, challenges, and frontiers. Fungal Biology Reviews, 21(2-3), 51-66. https://doi.org/10.1016/j.fbr.2007.05.003

Atugala, D.M. \& Deshappriya, N. (2015). Effect of endophytic fungi on plant growth and blast disease incidence of two traditional rice varieties. Journal of the National Science Foundation of Sri Lanka, 43(2), 173-187. https://doi.org/10.4038/jnsfsr.v43i2.7945

Benhamou, N., Gagne, S., Lequere, D. \& Dehbi, L. (2000). Bacterial-mediated induced resistance in cucumber: beneficial effect of the endophytic bacterium Serratia plymuthica on the protection against infection by Pythium ultimum. Phytopathology, 90 (1), 45-56. https://doi.org/10.1094/phyto.2000.90.1.45

Benitez, T., Rincon, A.M., Limon, M.C. \& Codon, A.C. (2004). Biocontrol mechanisms of Trichoderma strains. International Journal of Microbiology, 7 (4), 249-260. DOI:10.2436/im.v7i4.9480

Dennis, C. \& Webster, J. (1971). Antagonistic properties of species-groups of Trichoderma I. Production of volatile antibiotics. Transactions of the British Mycological Society, 57(1), 25-39. https://doi.org/10.1016/s0007-1536(71)80077-3

Di Pietro, A., Lorito, M., Hayes, C.K., Broadway, R.M. \& Harman, G.E. (1993). Endochitinases from Gliocladium virens: isolation, characterization and synergistic antifungal activity in combination with gliotoxin. Phytopathology, 83(3), 308-313. https://doi.org/10.1094/phyto-83-308

Dobranic, J.K., Johnson, J.A. \& Alikhan, Q.R. (1995). Isolation of endophytic fungi from eastern larch (Larix laricina) leaves from New Brunswick, Canada. Canadian Journal of Microbiology, 41(2), 194-198. https://doi.org/10.1139/m95-026

Domsch, K.H., Gams, W. \& Anderson, T.H. (1980). Compendium of Soil Fungi. Academic Press, New York, USA, pp. 1156. https://doi.org/10.1111/j.1365-2389.2008.010521.x

Dorothy, D.A. \& Kandikere, R.S. (2009). Assemblage and diversity of fungal associated with mangrove wild legume Canavalia cathartica. Tropical and Subtropical Agroecosystems, 10, 225-235. 
El-Hasan, A., Walker, J., Schone, J. \& Buchenaurer, H. (2009). Detection of viridiofungin A and other antifungal metabolites excreted by Trichoderma harzanium active against different plant pathogens. European Journal of Plant Pathology, 124(3), 457-470. https://doi.org/10.1007/s10658-009-94333

El-Morsy, E.M. (2000). Fungi isolated from the endorhizosphere of halophytic plants from Red Sea Coast of Egypt. Fungal Diversity, 5, 43-54. https://doi.org/10.2307/3761367

El-Nagerabi, S. A.F., Elshafie, A. E. \& Alkhanjari, S.S. (2013). Endophytic fungi associated with Ziziphus species and new records from mountainous area of Oman. Biodiversitas, 14(1): 10-16. https://doi.org/10.13057/biodiv/d140102

Fouda, A.H., Hassan, S.E.D., Eid, A.M. \& Ewais, E.E.D. (2015). Biotechnological applications of fungal endophytes associated with medicinal plant Asclepias sinaica (Bioss.). Annals of Agricultural Sciences, 60(1), 95-104. https://doi.org/10.1016/j.aoas.2015.04.001

Gashgari, R., Gherbawy, Y., Ameen, F. \& Alsharari, S. (2016). Molecular characterization and analysis of antimicrobial activity of endophytic fungi from medicinal plants in Saudi Arabia. Jundishapur Journal of Microbiology, 9(1), e26157. https://doi.org/10.5812/jjm.26157

Gherbawy, Y.A. \& Gashgari, R.M. (2014). Molecular characterization of fungal endophytes from Calotropis procera plants in Taif region (Saudi Arabia) and their antifungal activities. Plant Biosystems, 148(6),1085-92. https://doi.org/10.1080/11263504.2013.819043

Ghildial, A. \& Pandey, A. (2008). Isolation of cold tolerant antifungal strains of Trichoderma sp. from glacier sites of Indian Himalayan region. Research Journal of Microbiology, 3(8), 559-564. https://doi.org/10.3923/jm.2008.559.564

Gouda, S., Das, G., Sen, S. K., Shin, H. S. \& Patra, J. K. (2016). Endophytes: A Treasure House of Bioactive Compounds of Medicinal Importance. Frontiers in Microbiology, 7, 1538. https://doi.org/10.3389/fmicb.2016.01538

Harman, G.E., Howell, C.R., Viterbo, A., Chet, I. \& Lorito, M. (2004). Trichoderma species-opportunistic avirulent plant symbionts. Nature Reviews Microbiology, 2(1), 43-56. https://doi.org/10.1038/nrmicro797

Hosseyni-Moghaddam, M.S. \& Soltani, J. (2014). Bioactivity of endophytic Trichoderma fungal species from the plant family Cupressaceae. Annals of Microbiology, 64(2), 753-761. https://doi.org/10.1007/s13213-013-0710-1

Johnston, P.R., Johansen, R.B., Williams, A.F., Wikie, J.P.\& Park, D. (2012). Patterns of fungal diversity in New Zealand Nothofagus forests. Fungal Biology, 116(3), 401-12. https://doi.org/10.1016/j.funbio.2011.12.010

Katoch, M. \& Pull, S. (2017). Endophytic fungi associated with Monarda citriodora, an aromatic and medicinal plant and their biocontrol potential. Pharmaceutical Biology, 55(1), 1528-1535. http://dx.doi.org/10.1080/13880209.2017.1309054

Katoch, M., Phull, S., Vaid, S. \& Singh, S. (2017). Diversity, phylogeny, anticancer and antimicrobial potential of fungal endophytes associated with Monarda citriodora L. BMC Microbiology, 17(1), 44-57. https://doi.org/10.1186/s12866-017-0961-2

Kumar, D. \& Hyde, K.D. (2004). Biodiversity and tissue-recurrence of endophytic fungi in Tripterygium wilfordii. Fungal Diversity, 17, 69-90.

Lata, R., Chowdhury, S., Gond, S. \& White, J. F. (2018). Induction of abiotic stress tolerance in plants by endophytic microbes. Letters in Applied Microbiology, 66(4), 268-276. https://doi.org/10.1111/lam.12855

Li, H.M., Sullivan, R., Moy, M., Kobayashi, D.Y. \& Belanger, F.C. (2004). Expression of a novel chitinase by the fungal endophyte in Poa ampla. Mycologia, 96(3), 526-536. https://doi.org/10.1080/15572536.2005.11832951

Mandyam, K. \& Jumpponen, A. (2005). Seeking the exclusive function of the root-colonising dark septate endophytic fungi. Studies in Mycology, 53, 173 - 189. https://doi.org/10.3114/sim.53.1.173

Molina, G., Pimentel, M.R., Bertucci, T.C.P. \& Pastore, G.M. (2012). Application of fungal endophytes in biotechnological processes. Chemical Engineering Transactions, 27, 289-294. https://doi.org/10.3303/CET1227049. 
Pandya, U. \& Saraf, M. (2010). Application of fungi as a biocontrol agent and their bio fertilizer potential in agriculture. Journal of Advance Development and Research, 1(1), 90 - 99.

Kembel, S.W. \& Mueller, R.C. (2014). Plant traits and taxonomy drive host associations in tropical phyllosphere fungal communities. Botany, 92(4), 303- 311. https://doi.org/10.1139/cjb-2013-0194.

Petrini, O. \& Fisher, P.J. (1988). A comparative study of fungal endophytes in xylem and whole stem of Pinus sylvestris and Fagus sylvatica. Transactions of the British Mycological Society, 91(2), 233-238. https://doi.org/10.1016/s0007-1536(88)80210-9

Phongpaichit, S., Nikom, J., Rungjindamai N., Sakayaroj, J., Hutadilok-Towatana, N., Rukachaisirikul, V. \& Kirtikara, K. (2007). Biological activities of extracts from endophytic fungi isolated from Garcinia plants. FEMS Immunology \& Medical Microbiology, 51(3), 517-525. https://doi.org/10.1111/j.1574-695x.2007.00331.x

Porras, A.A. \& Bayman, P. (2011). Hidden fungi, emergent properties: endophytes and microbiomes. Annual Review of Phytopathology, 49(1), 291-315. https://doi.org/10.1146/annurev-phyto-080508-081831

Prathyusha, P., Rajitha, A.B. \& Satya Prasad, K. (2015). Diversity and enzymatic activity of foliar endophytic fungi isolated from medicinal plants of Indian dry deciduous forest. Der Pharmacia Lettre, 7(8),244-251. ISSN 0975-5071

Radji, M., Sumiati, A., Rachmayani, R. \& Elya, B. (2011). Isolation of fungal endophytes from Garcinia mangostana and their antibacterial activity. African Journal of Biotechnology, 10(1), 103-107. https://doi.org/10.5897/AJB10.1531

Rodriguez, R.J., White, J.F., Arnold, A.E. \& Redman, R.S. (2009). Fungal endophytes: diversity and functional roles. New Phytologist, 182(2), 314-330. https://doi.org/10.1111/j.1469-8137.2009.02773.x

Samuels, G. J. (1996). Trichoderma: a review of biology and systematics of the genus. Mycological Research, 100(8), 923-935. https://doi.org/10.1016/s0953-7562(96)80043-8

Sandhu, S.S., Suneel, K., Aharwal, R.P., Shukla, H. \& Rajak, R.C. (2014). Endophytic Fungi: As A Source of Antimicrobials Bioactive Compounds. World Journal of Pharmacy and Pharmaceutical Sciences, 3(2), 1179-1197.

Selim, K.A., El-Beih, A.A., AbdEl-Rahman, T.M. \& El-Diwany, A.I. (2012). Biology of endophytic fungi. Current Research in Environmental and Applied Mycology, 2(1), 31-82. Doi 10.5943/cream/2/1/3

Singh, L.P., Gill, S.G. \& Tuteja, N. (2011). Unraveling the role of fungal symbionts in plant abiotic stress tolerance. Plant Signaling and Behavior, 6(2),175-191. https://doi.org/10.4161/psb.6.2.14146

Sternberg, D. \& Doval, S. (1980). Cellulase production and ammonia metabolism in Trichoderma reesei on high levels of cellulose. Biotechnology and Bioengineering, 21(2), 181-192. https://doi.org/10.1002/bit.260210205

Sudha, V., Govindaraj, R., Baskar, K., Al-Dhabi, N.A. \& Duraipandiyan, V. (2016). Biological properties of Endophytic Fungi. Brazilian Archives of Biology And Technology, 59, e16150436. https://doi.org/10.1590/1678-4324-2016150436

Sun, X., Ding, Q., Hyde, K.D., \& Guo, L.D. (2012). Community structure and preference of endophytic fungi of three woody plants in a mixed forest. Fungal Ecology, 5(5), 624-632. https://doi.org/10.1016/j.funeco.2012.04.001

Talapatra, K., Das, A.R., Saha, A.K. \& Das, P. (2017). In vitro antagonistic activity of a root endophytic fungus towards plant pathogenic fungi. Journal of Applied Biology \& Biotechnology, 5(2): 68-71. https://doi.org/10.7324/jabb.2017.50210

Theantana, T., Hyde, K.D. \& Lumyong, S. (2007). Asparaginase production by Endophytic fungi isolated from some Thai medicinal plants. KMITL Science and Technology Journal, (S1):13-18.

Ting, A.S.Y., Mah, S.W. \& Tee, C.S. (2010). Identification of volatile metabolites from fungal endophytes with biocontrol potential towards Fusarium oxysporum F. sp. cubense Race 4. American Journal of Agricultural and Biological Sciences, 5(2),177-182. https://doi.org/10.3844/ajabssp.2010.177.182

Toghueo, R.M.K., Zabalgogeazcoa, I., Vázquez de Aldana, B.R. \& Boyoma, F.F. (2017). Enzymatic activity of endophytic fungi from the medicinal plants Terminalia catappa, Terminalia mantaly and Cananga odorata. South African Journal of Botany, 109, 146-153. https://doi.org/10.1016/j.sajb.2016.12.021 
Walters, D., Walsh, D., Newton, A. \& Lyon, G. (2005). Induced resistance for plant disease control: maximizing the efficacy of resistance elicitors. Phytopathology, 95(12), 1368-1373. https://doi.org/10.1094/phyto-95-1368

Whipps, J.M. (2001). Microbial interactions and biocontrol in the rhizosphere. Journal of Experimental Botany, 52(1), 487-511. https://doi.org/10.1093/jxb/52.suppl_1.487

Wiyakrutta, S., Sriubolmas, N., Panphut, W., Thongon, N., Danwisetkanjana, K., Ruangrungsi, N. \& Meevootisom, V. (2004). Endophytic fungi with anti-microbial, anti-cancer and anti-malarial activities isolated from Thai medicinal plants. World Journal of Microbiology and Biotechnology, 20(3), $265-72$. https://doi.org/10.1023/b:wibi.0000023832.27679.a8

\section{Copyrights}

Copyright for this article is retained by the author(s), with first publication rights granted to the journal.

This is an open-access article distributed under the terms and conditions of the Creative Commons Attribution license (http://creativecommons.org/licenses/by/4.0/). 